\title{
Cervical Priming with Hydroscopic Dilatator Before Hysteroscopy: Effect on Pain Scores and Ease of the Procedure
}

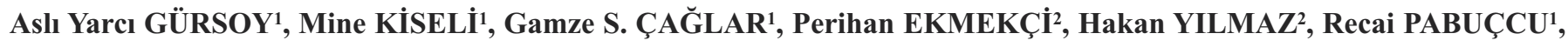 \\ Sevim DINÇER CENGIZ ${ }^{1}$
}

Ankara, Turkey

\begin{abstract}
OBJECTIVE: Aquacryl hydrogel is one of the cervical dilatators which is a synthetic rigid hydroscopic gel rod, indicated to be used for cervical preparation. The authors aimed to determine whether preoperative cervical preparation with Aquacryl hydrogel before hysteroscopy has any favorable effects either for the patient (pain scores) or for the surgeon (ease of the procedure).
\end{abstract}

STUDY DESIGN: The randomized controlled trial was undertaken in the Obstetrics and Gynecology Department of a University Hospital setting. Forty-three reproductive age women scheduled for hysteroscopy due to gynecological indications were randomized to receive hydroscopic dilatators for cervical preparation $(n=19)$ or no intervention before the procedure $(n=27)$. Visual analog scale (VAS) was used to evaluate pain scores until the operation. Analgesic administration was done in case of a VAS score $\geq 40$ or patients' demand for analgesia. Intraoperatively, mean arterial pressure and pulse were documented in order to evaluate analgesic requirement.

RESULTS: Median VAS scores at hydroscopic dilatator administration $0^{\text {th }}, 1^{\text {st }}, 2^{\text {nd }}, 3^{\text {rd }}$, and $4^{\text {th }}$ hours after insertion were $29 \pm 24(0-80), 14 \pm 15(0-6), 13 \pm 15(0-5), 8 \pm 9(0-30)$ and $5 \pm 9(0-3)$, respectively; where pain scores significantly decreased in time $(p<0.05)$. There was no significant difference between mean arterial pressure and heart rate values between groups throughout the preoperative and intraoperative follow up ( $p>0.05)$.

CONCLUSIONS: This study revealed that, Aquacryl hydrogel for cervical priming before office hysteroscopy is not effective to reduce the pain of patients' during the procedure but also does not ease access to the uterine cavity. Therefore, it is not advantageous for the patient to use this agent before hysteroscopy.

Keywords: Hydroscopic dilatator, Hysteroscopy, Pain, Cervical priming

Gynecol Obstet Reprod Med 2016;22(3):149-151 DOI: 10.21613/GORM.2016.68

\section{Introduction}

Many interventions in Obstetrics and Gynecology practice require cervical priming to ease the procedure. Although some medications (1) (e.g.prostaglandins, nitric oxide donors) and mechanical dilatators have been proposed for cervical priming, none has been proven to have superior efficacy and patient comfort (2). Aquacryl hydrogel is one of the mechanically acting dilatators which is a synthetic rigid hydroscopic

\footnotetext{
1 Ufuk University Faculty of Medicine, Obstetrics and Gynecology Department, Ankara

2 Ufuk University Faculty of Medicine, Anesthesiology and Reanimation Department, Ankara

Address of Correspondence: Aslı Yarcl Gürsoy

Ufuk University Faculty of Medicine,

Department of Obstetrics and

Gynecology Balgat Ankara, Turkey

asliyarci@gmail.com
}

Submitted for Publication:

08. 04.2016

Accepted for Publication:

29. 04.2016 gel rod, indicated to be used for cervical preparation either for obstetric indications such as preinduction of labour, termination of pregnancy for medical reasons or for gynecological indications such as insertion or removal of an intrauterine device or hysteroscopy (3). The main mechanism of action of Aquacryl hydrogel is, absorption of water from the surrounding cervical tissue resulting with expansion of the rod in diameter and also softening of the cervical tissue. Secondarily, the widened rod exerts a radial outward force which widens the cervical canal (4).

Nowadays, office hysteroscopy is widely applied gynecological intervention performed for a variety of indications. The application of hydroscopic dilatator before hysteroscopy might ease access to the endometrial cavity through the cervical canal. Owing to lack of any prospective randomized studies evaluating the value of this approach, we aimed to determine whether preoperative cervical preparation with Aquacryl hydrogel has any favorable effects either for the patient (pain scores) or for the surgeon (ease of the procedure). 


\section{Material and Method}

The study was approved by the local Ethical Committee and randomized controlled trial was registered to ANZCTR (Autralian New Zealand Clinical Trials Registry) with the clinical trial number ACTRN12615000484549. The study was undertaken in the University Obstetrics and Gynecology Department between April 2015-April 2016. The target sample size was 60 patients but the study was stopped at 46 subjects due to financial problems.

The exclusion criteria were previous cervical surgery, history of cervical insufficiency, presence of cervical premalignant lesions, need for operative hysteroscopy, mental function impairment which may lead insufficient evaluation of pain scores, being on chronic opiod medication, serious systemic diseases. The indications of hysteroscopy were menstrual cycle irregularities, infertility and endometrial polyp (Table 1). Forty-three reproductive age women scheduled for hysteroscopy were randomized to receive hydroscopic dilatators for cervical preparation $(n=19)$ or no intervention before the procedure $(n=27)$. The allocation was concealed by sealed opaque envelopes. The rod shaped hydroscopic dilatator (Dilapan$\mathrm{S}^{\circledR}$, MEDICEM International $\mathrm{GmbH}$, Switzerland) was administered through the cervical canal by grasping via the distal end of the rod to which the string was attached and the patient was observed preoperatively for about 4 hours. Visual analog scale (VAS) was used to evaluate pain scores until the operation. Analgesic administration was done in case of a VAS score $\geq 40$ or patients' demand for analgesia.

Intraoperatively, after the routine monitorization of the patient, induction for anesthesia was done by $3 \mathrm{mg} / \mathrm{kg}$ propofol and Desfluran and

Table 1: Demographic variables and indications for hysteroscopy

\begin{tabular}{|c|c|c|c|}
\hline & $\begin{array}{l}\text { Study Group } \\
\qquad(\mathrm{n}=19)\end{array}$ & $\begin{array}{c}\text { Control Group } \\
(n=27)\end{array}$ & $\mathrm{p}$ \\
\hline Age (mean $\pm S D)$ & $40.1 \pm 7.9$ & $37.6 \pm 9.3$ & 0.335 \\
\hline Gravidity (median[min-max]) & $2[0-7]$ & $1[0-10]$ & 0.055 \\
\hline Parity (median[min-max]) & $2[0-5]$ & $1[0-5]$ & $0.043^{*}$ \\
\hline Abortion (median[min-max]) & $0[0-4]$ & 0 [0-2] & 0.901 \\
\hline D\&C (median[min-max]) & 0 [0-2] & $0[0-6]$ & 0.458 \\
\hline Livebirth (median[min-max]) & $2[0-5]$ & $0[0-3]$ & $0.005^{*}$ \\
\hline \multicolumn{4}{|l|}{ Indication for hysteroscopy (n) } \\
\hline Endometrial polyp & 10 & 10 & \\
\hline Infertility & 0 & 3 & \\
\hline Menstrual cycle irregularities & 9 & 14 & \\
\hline
\end{tabular}

$* p<0.05$

Table 2: Analgesic requirement and surgeon satisfaction scores

\begin{tabular}{l|c|c|c|}
\hline & $\begin{array}{c}\text { Study Group } \\
(n=19)\end{array}$ & $\begin{array}{c}\text { Control Group } \\
(n=27)\end{array}$ & $p$ \\
\hline Preoperative analgesic requirement & $4(\% 21.1)$ & - & $0.024^{*}$ \\
Intraoperative analgesic requirement & $2(\% 10.5)$ & $6(\% 22.2)$ & 0.440 \\
Total analgesic requirement & $6(\% 31.6)$ & $6(\% 22.2)$ & 0.513 \\
Surgeon satisfaction score $(1-5)$ & $4.6 \pm 0.7$ & $4.3 \pm 1.0$ & 0.358 \\
\hline${ }^{*} p<0.05$ & & &
\end{tabular}

air/oxygen combination was used for maintenance. Mean arterial pressure and pulse were documented before and throughout the operation in order to evaluate analgesic requirement. In case of elevation in systolic blood pressure or heart rate over $20 \%$ of the baseline values, the patient was assumed to have sympathetic system activation due to pain and $50 \mathrm{mg}$ meperidine was administered intravenously. In all cases, access to the uterine cavity was performed by vaginoscopic technique by the $5 \mathrm{~mm}$ rigid hysteroscope (Storz ${ }^{\circledR}$, Germany). The surgeons evaluated the ease of the procedure, which is classified as surgeon satisfaction in Table 2, using a 5-point numerical scale 1 meaning the worst and 5 meaning the best.

SPSS for Windows version 22.0 was used to analyse the data. Numerical variables were given as mean $\pm \mathrm{SD}$ or median [min-max] and numbers or percentiles where appropriate. The mean differences between groups were compared by Student's t test. Otherwise, Mann Whitney U test was applied for the comparisons of the median values. Chi-square test was used to evaluate the difference for qualitative variables. Alteration in mean arterial pressure, pulse rate and VAS scores were evaluated by Friedman test. A p value $<0.05$ was considered statistically significant.

\section{Results}

Median VAS scores at hydroscopic dilatator administration $0^{\text {th }}, 1^{\text {st }}, 2^{\text {nd }}, 3^{\text {rd }}$, and $4^{\text {th }}$ hours after insertion were $30(0-80), 10(0-60), 10(0$ - 50), $5(0-30)$ and $0(0-30)$, respectively; where pain score significantly decreased in time (Figure 1, $\mathrm{p}<0.05$ ). There was no significant difference between mean arterial pressure and heart rate values between groups throughout the preoperative and intraoperative follow up ( $p>0.05)$. Before the operation, higher number of cases required analgesia in study group compared to controls (4 vs 0 patients; $\mathrm{p}=0.024$ respectively) (Table 2). Intraoperative ( 6 vs 2 patients, $\mathrm{p}=0.44$ ) and total analgesic consumption ( 6 vs 6 patients, $p=0.513$ ) were similar between study and control groups No complications related with the hydroscopic dilatator occured during the course of the study. The hydroscopic dilatator did not ease the access to uterine cavity through the cervix. The scores of 5-point numerical scale of the surgeons were not different in cases with or without hydroscopic dilatator $(\mathrm{p}>0.05)$. 


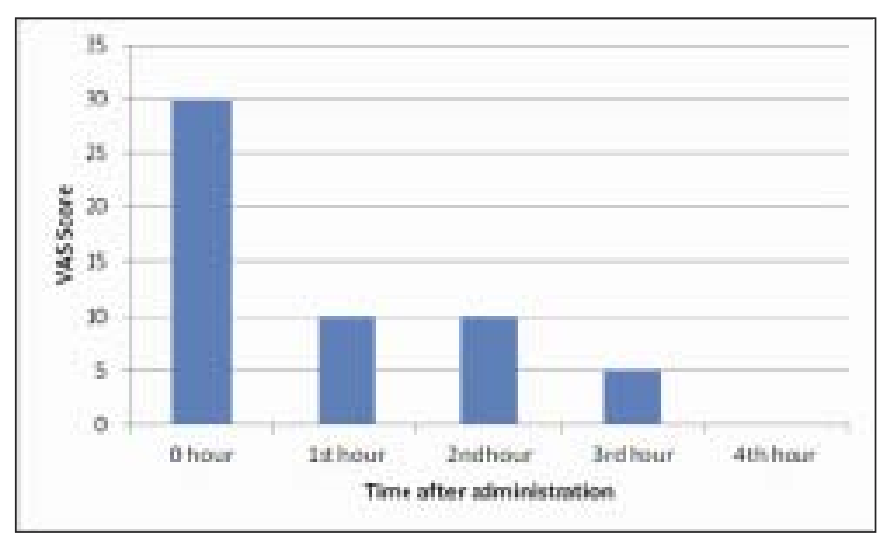

Figure 1: The preoperative changes in visual analogue scale scores after aquacryl hydrogel administration

\section{Discussion}

Cervical preparation with hydroscopic dilatators, increases preoperative VAS scores and the need for preoperative analgesic administration. VAS scores in the study group seem to gradually decline suggesting that the application as the main trigger for the pain sensation. Also, indirect signs of pain, like mean arterial pressure or pulse rate changes indicate that, no intraoperative favorable effect for the patient exists. Moreover, for the operators, this intervention does not ease access to the uterine cavity for the defined technique.

Cervical priming before office hysteroscopy with different doses and routes of adminstration of prostaglandin analogues and progesteron receptor antagonists (misoprostol, dinoprostone, mifepristone) have been the subject of interest (6-8). But mechanical dilatators such as Aquacryl hydrogel which is the interest of the current study have not been evaluated enough in this aspect. Value of cervical preparation before outpatient hysteroscopy to reduce patients'pain experience has been evaluated by a recent review by Cooper NA et al (9). The 6 trials included in the analysis concluded there is no evidence to suggest routine use of these agents but cervical priming with misoprostol might be considered in postmenopausal women who would be operated by hysteroscopic systems greater than $5 \mathrm{~mm}$. As the administration of the Aquacryl hydrogel is usually successful in reproductive age women, the current study included premenopausal women undergoing office hysteroscopy. However, a stenotic and atrophic postmenopausal cervical canal technically disrupts this application in most of the cases. As a limitation, route of delivery of the included patients were not documented which might reflect the resistance in the cervical canal and effect the appropriate application of the device but also ease of the procedure. Another limitation might be evaluation of the ease of the procedure by three different surgeons. Although the technique of hysteroscopy is standardized, personal bias might have an effect on the results of the current study.

Hydroscopic dilatators have been blamed with many adverse events such as infections, fragmentation, and anaphylaxis
(2). Infections are mostly associated with natural osmotic dilatator agents like luminaria. The key point to avoid these complications might be administration of the Aquacryl hydrogel under control and do not keep the device for extreme periods. In this study, none of the mentioned complications were reported and all the devices were removed before the $4^{\text {th }}$ hour of the application. The limited time of application might help to prevent complications related with fragmentation of the device.

This study revealed that, Aquacryl hydrogel for cervical priming before office hysteroscopy is not effective to reduce the pain of patients' during the procedure. The application of this device is not pain free but quite well tolerated by the patients. After the application nearly $20 \%$ of the cases required analgesia before hysteroscopy. Therefore, it is not advantageous for the patient to use this agent before hysteroscopy. Finally, limited time of exposure is not associated with complications when used for cervical priming.

\section{References}

1. Chen FC, Bergann A, Krosse J, Merholz A, David M. Isosorbide mononitrate vaginal gel versus misoprostol vaginal gel versus Dilapan-S for cervical ripening before first trimester curettage. Eur J Obstet Gynecol Reprod Biol 2008;138(2):176-9.

2. Lichtenberg ES. Complications of osmotic dilators. Obstet Gynecol Surv 2004;59(7):528-36.

3. http://www.dilapan.com/en/indications

4. McCord ML, Stovall TG, Summitt RL Jr, Lipscomb GH, Collins KW, Parsons LH. Synthetic hygroscopic cervical dilator use in patients with unsatisfactory colposcopy. Obstet Gynecol 1995;85(1):30-2.

5. Di Spiezio Sardo A, Guida M, Pellicano M, Nappi C, Bettocchi S. New technique to perform hysteroscopy in 'women with an intact hymen' is really just the vaginoscopic approach (no-touch technique). J Minim Invasive Gynecol 2006;13(5):489-90.

6. Xu D, Zhang X, He J.A Prospective, Randomized Comparison of Intramuscular Phloroglucinol Versus Oral Misoprostol for Cervix Pretreatment Before Diagnostic Hysteroscopy. Int Surg 2015;100(7-8):1207-11.

7. Inal HA, Ozturk Inal ZH, Tonguc E, Var T. Comparison of vaginal misoprostol and dinoprostone for cervical ripening before diagnostic hysteroscopy in nulliparous women. Fertil Steril 2015;103(5):1326-31.

8. Lee YY, Kim TJ, Kang H, Choi CH, Lee JW, Kim BG et al. The use of misoprostol before hysteroscopic surgery in non-pregnant premenopausal women: a randomized comparison of sublingual, oral and vaginal administrations. Hum Reprod 2010;25(8):1942-8.

9. Cooper NA, Smith P, Khan KS, Clark TJ. Does cervical preparation before outpatient hysteroscopy reduce women's pain experience? A systematic review. BJOG 2011;118(11):1292-301. 